\title{
Differentiation of post streptococcal reactive arthritis from acute rheumatic fever
}

\author{
J Barash *1,7, E Mashihach ${ }^{1}$, P Navon-Elkan², Y Berkun ${ }^{3}$, L Harel $^{4}$, T Tauber ${ }^{5}$, \\ S Padeh ${ }^{3}$, PJ Hashkes ${ }^{6}$ and Y Uziel ${ }^{1}$
}

Address: ${ }^{1}$ Kaplan Medical Center, Rehovot, Israel, ${ }^{2}$ Shaarei Zedek Medical Center, Jerusalem, Israel, ${ }^{3}$ Sheba Medical Center, Tel Hashomer, Israel, ${ }^{4}$ Schneider Children's Hospital, Petah Tikva, Israel, ${ }^{5}$ Asaf Harofeh Medical Center, Zrifin, Israel, ${ }^{6}$ Cleveland Clinic, Cleveland, USA and ${ }^{7}$ Meir Medical Center, Kfar Saba, Israel

* Corresponding author

from I5 ${ }^{\text {th }}$ Paediatric Rheumatology European Society (PreS) Congress

London, UK. 14-17 September 2008

Published: 15 September 2008

Pediatric Rheumatology 2008, 6(SuppI I):PI98 doi:10.II86/1546-0096-6-SI-PI98

This abstract is available from: http://www.ped-rheum.com/content/6/SI/PI98

(C) 2008 Barash et al; licensee BioMed Central Ltd.

\section{Objective}

We performed a retrospective study comparing clinical and laboratory aspects of patients with acute rheumatic fever (ARF) and post streptococcal reactive arthritis (PSRA), in order to answer the question whether these are two separate entities or varying clinical manifestations of the same disease.

\section{Study design}

We located through the Israeli internet based paediatric rheumatology registry 68 patients with ARF and 159 patients with PSRA, treated by 8 paediatric rheumatologists. The medical records of these patients were reviewed for demographic, clinical and laboratory variables and the data compared and analyzed by univariate, multivariate and discriminatory analysis.

\section{Results}

Four variables were found to differ significantly between ARF and PSRA and serve also as predictors: sedimentation rate, C-reactive protein, duration of joint symptoms after starting anti-inflammatory treatment and relapse of joint symptoms after cessation of treatment. A discriminative equation was calculated which enabled us to correctly classify more than $80 \%$ of the patients.

\section{Conclusion}

Based on simple clinical and laboratory variable we were usually able to differentiate ARF from PSRA. It appears that they are different entities, although both are associated with streptococcal infection and involve the joints. 